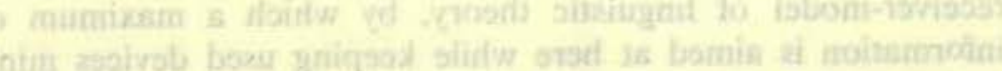 \\ MISTAKES AND "MISTAKES": TO THE AMBIVALENCE OF MISTAKES. A PROOF OF THESES
}

by Peter JÜNGEL

TÜBIGEN

WEST-GERMANY

In my doctoral thesis (in prep.) I discuss in an appendix (title: Mistakes and "Mistakes": To the ambivalence of mistakesmethodological problems at the example Codex Madrid 75-76 (orig. in German) whether a correction of mistakes can uncritically be done. This is done as an examplarian study of methods analysing mistakes at the example of the cartouche of day-signs (named thus by me) that is arranged around the central picture. (The correction itself isn't affected or doubted). Taken a casual distribution of the mistakes there as decisive criterion, one finds facts that can't be decided or are contradictory in tendency to the aim. At last, as result of case studies, it had to be concluded that the mistakes are intentional, set in directedly and can be interpreted without any contradiction in Codex Madrid (short: $\mathrm{CM}$ ) as a reflex of the shift of yearbearers, and, second place, taken the numerical equivalents of the day-signs in the long-count, as a system grouping sidereal months. While there especially interested in the consequences in respect of the grades of complexity of texts and systems in Mesoamerican codices and Maya-inscriptions, a possible objection against result and election of CM 75-76 as object of study will be prooved on the soundness of its foundation. This objection might be formulated like this: The source CM 75-76 is because of faultyness and hasty of its drawing-style unreliable and therefore unfit for such an examination. Against this I shall set the antitheses that the Maya-scribe is more reliable than he is known for in science; and still more, these mistakes are a form of coding in the sense of the well-known transmitter- 
receiver-model of linguistic theory, by which a maximum of information is aimed at here while keeping used devices minimal. Owing to circumstances the author operates with the foreknowledge of the reader and member of the same culture as part of the whole of information. My aim is to test the antitheses in respect of soundness and eventually falsify the objection. 76.

Before going into detail I will shortly introduce to CM 75-

There are four pictures set at the borders of a central fifth ending in an arrangement of a cross and representing the world-directions. A ritual-calendar (RC) surrounds this cross and runs in form of a maltese-cross. The RC is parted into its 20 Trecenas which each consist of a row of points and the named initial and final days. Around the central picture we find the cartouche of day-signs already analysed (P. Jüngel: in prep.) which, at least intentionally, adjoins the day-signs to world-directions. But these day-signs are $180^{\circ}$ away from their correct directions as known from other sources. There is no explanation for this (yet). Further on in between of the run of the RC feet or footprints with white borders and points of two sizes make up the chapter; latter can be called "toes".

The chapter CM 75-76 possesses a parallel in Codex Fejérváry-Mayer (CFM) 1, but differs in a number of detils from the more reliable CFM 1 (see E. Seler 1901:5-31) which surely is nearer to an original composition. These differences often are caused by the "faultyness" of CM 75-76.

Because of the aims of the study CFM 1 will only casually be mentioned and examined.

Starting with my "proof of theses" I'll study the RC at first.

The Trecenas - a controversy on the length of their rows of points.

The RC runs counterclockwise around the pictures and is parted in 20 parts of 13 days length, the Trecenas. It commences in the lower left corner. The first three Trecenas describe the outer borders of the east-side picture, i.e. the lower picture. The next two Trecenas are forming a turn into the following lower right corner. This is repeated thrice, for each world-direction once, the center excluded. 
Five Trecenas in the series as described belong to one direction. The result is the form of the maltese-cross as in CFM 1. As E. Seler $(1901: 29)$ correctly noted, the trapezoidal pictures of the directions are deformed in counterclockwise direction, i.e. the direction the RC takes. There are named the initial and final days of the Trecenas, latter are missing as well as the day-numbers of the former in CFM 1 . In between each pair of them runs a row of points. While in CFM 1 their length is 12 points, so that they fill up the Trecenas, there is a controversy on what is intended and what the actual is and means in CM 75-76. Thompson (1950:247-248) believes, it is 12 points, Thies $(1979: 265)$ because of the naming of the final days argues for a number 11 as intended. So much is to be noticed by former researches, there are rows of 11,12 and 13 points (Thies: 1979:264). In general opinion this is a case of faulty copying or faulty writing, though this argue can't solve the controversy, if the equivalence of one point one day is taken for granted as in CFM 1 and which I do not doubt.

How do these different opinions come to exist?

Thies, thought possibly partially counting, arrives to her opinion by logical deduction:

The number of days separating initial and final day of a Trecena is 11 .

Therefore 11 points has to be accepted as the intended number.

Thompson, possibly on a partial counting as well, arrives to his statement by analogy:

In CEM 1 the lenght is 12 points. Here do exist sections of 12 points. Because of the other formal identities in composition to CEM 1 the count " 12 " is the intended.

Other researchers might have come to one of these or another opinion on a basis of a counting of all examples (which Thompson and Thies might also have done thought at the end being less important in their argumentation) and a later statistical generalisation or by a casual counting of statistical significance, which, in the latter case, might have offered a clear solution in favour of a "length 13 points". 
This controversy - logical deduction (Thies) versus analogy (Thompson), whose principal weakness cannot be doubted, versus eventual case study - can only be solved by counting all rows and statistical interpretating.

The facts are this:

12 of 20 Trecenas have the lenght 12 points, 6 are of length 13 and only. 2 of lenght 11 points.

The statistical valuation prooves Thompson distinctly but only by disprooving Thies's opinion as the most seldom case. Thies's deduction is devaluated but not replaced because the normal case mounts to only $60 \%$.

On a higher niveau of information there must exist a statement which replaces Thies's doubtless logical deduction and gives another explanation for the existence of the final days of the Trecenas, if the statistical result should have a real background. This is only, if possible at all, by qualitative interpretation. Criterion of evaluation will be firsthand a principle of positional preferences, eventual other criterions if needed must be notice.

It happens to be in chronological order of representation:

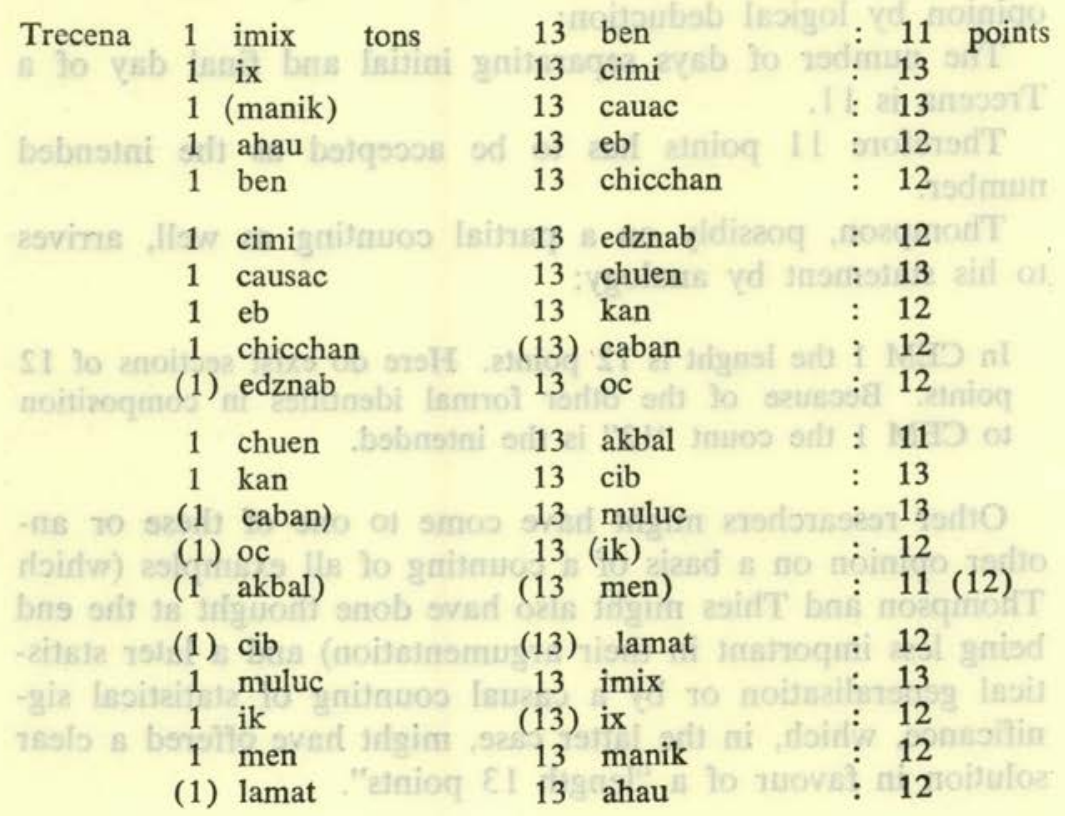


For the fifteenth Trecena, i.e. 1 akbal - 13 men, partially affected by destruction, one point, towards the normal case, can be restored because of the distribution of the lengths of 11,12 and 13 points. To the seventh Trecena, i.e. 1 cauac 13 chuen may be attached one point that is to be found half on the border of the cartouche of the day 13 edznab towards the next page and which is somewhat isolated from both, the sixth and the seventh Trecena. This can be done because of the systemacy of distribution. ${ }^{1}$

The arrangement in RC-quaters does not only clear the situation for comparison but marks the distribution of Trecenas to world-directions as well.

A system can be recognized and described as followed:

The last two Trecenas of a RC-Quarter have always length 12 , the second always 13 points. The appearances of 11 points, which are as mentioned only two, are the first and the 11th Trecena. Obviously to keep the sum of points in a RC-quarter at 61 points there are filled up the third Trecenas of the first and third RC-quarter to 13 points. (A reversal of the argumentation is possible before the interpretation but because of reasons of content less likely.) As the 6 th and 16 th Trecenas are of length 12 , the 8 th and the 18 th Trecenas only need to be of length 12 .

How are the facts to interpreted?

The situation of the Trecenas of 11 points diagonal opposed speaks in favour of marking start and second half of the RC, i.e. the two halfs of the RC in contrast to the four quarters made by the distribution to the four world-directions.

The 13 points of the second Trecenas of the RC-quarter mark the points where the pictures touch the borders of the pages. Insofar this is firsthand remarkable in respect of positional preferences. Do the regents of these Trecenas possess special meaning or importance which could justify their further accentuation by changing their number of points? I think, that's the case. For this we have to look on CFM 1. The year-

1 Is there intended a special role for I cauac by this deplacement, this in analogy to the day-sign cauac in the cartouche of the day-signs that is opposed in its positional preference to the other members of the Puuc-style year-bearers? (see for comparison P. Jüngel: in prep.) 
bearers of the regents of Trecenas stand in the corners of the diagonals and are marked as those. In CM 75-76 the same days are found in the corners of their world-direction which is the same as in CFM 1, i.e. ben belongs to the east as its CFM 1 equivalent reed does as well. The same holds true for akbal to the west, lamat to the south and edznab to the north. If the notice "year-bearers" can be adopted from CFM $1,{ }^{2}$ which has support from the analysis of the cartouche of the day-signs, the regents of the marked Trecenas can tentatively taken as representing the Puuc-system of year-bearers as reported by Landa (Tozzer: 1941:135). Both systems, the classic-time in the corners and the Puuc-style, are known in CM, directly the Puuc-style in CM 34-37 from the chapter of ceremonies for the new year, indirectly the classic-style in CM $65-73 \mathrm{~b}$ by the calendar round (CR)-date 13 ahau 13 Cumku (CM 73b), that is in the same source as a whole. This second accentuation of both systems in this chapter proposes a setting in relationship and in contrast for them, though $\mathrm{CM}$ is a cumulative manuscript and the different parts in it might be of quite different age of authorship as well as writing. Whether this notice can be used for a relative chronology of collecting the single chapters and for the development of CM 75-76 (or its model respectively) must be prooved in future.

The sum of all points is 244 or $4 \times 61$. Only as Inferior Conjunction and formal visibility of $236^{\mathrm{d}}$ of Morningstar-Venus this number caln be given any meaning so far. 61 points for each direction, a number which obviously had to be respected and therefore must be meaningful, if not the sum of 244 alone was meant, might be interpreted as 61 mean synods of Venus after which a correction of $4^{\mathrm{d}}$ had to be done (Thompson: 1972:62f.). This leads to a not satisfying interpretation "mean synod of Venus" that therefore has to be given up until there will be better evidence for such a theme.

Following the model of CFM 1 it has to be stated that 12 points are the normal case in principle. Because of a suspected intention to give more information (only because of this can be understood a systemacy of changements following a prin-

2 With this an interethnic adaptation and usage of results is tried (see P. Jüngel: in prep.). 
ciple of positional preferences) a length 11 had to be chosen for the axis begin and haltume of the RC thereby facing the problem of keeping clarity while fulfilling concurring intentions. This length 11 however would have ended in incomplete Trecenas. Therefore, 1 suppose, the final days of the Trecenas were needed twice. The rest of them was added for reasons of compositarian baiance though they also could have got a function and meaning in sequence.

Thies's logical deduction thus is replaced on a higher level of connecting given pieces of information by another explanation. The mistakes are "mistakes" and only could be taken for casual mistakes because of insufficient methodological study of the source. Numbers which have to be found by counting are to be asked for systemacy or the contrary before they can be used or excluded. (This is also true for other forms of information.) These numbers in connection with other pieces of information offer a clue for the direction of interpretation.

In respect to the theses given at the beginning it has to be stated: The theses are prooved, once. The writer is more reliable than believed, the author used the principle a maximum of information by a minimum of devices. The mistakes decode themselves as intended on a higher level of understanding, as directly set in and give support to "mistake-writing as medium of communication". Again, the author used the forenknowledge of the interpreter, intentionally, in a way that the normal length of the rows could be gained out of the source. The changes need the interpretation; to do this knowledge from other sources can be used.

More important for further study on this part a new perspective for the stagnanting research is given.

\section{THE FOOTPRINTS}

These results are to be tested once more. For this I shall turn to the representations of footprints which are embedded in the rows of points of the RC. This element I have hardly found treated in literature. Seler $(1901: 28-31)$ does not mention them at all, Thompson (1950:247-50) obviosly as well. Only Nowotny $(1961: 227)$ takes notice of them. For this reason this detail seems appropriate for such a further test. 
18 feet are depicted in paired form. They stand in the diagonals of the chapter opposing each other. In the middle of the pairs one row of points runs. There are 9 right and 9 left feet. With the exception of the upper right corner where are 3 pairs there are always 2 pairs in a corner. But these pairs consist of 3 pairs that are made of only right, respectively of only left feet and three of natural pairs: Is that a mistake?

1. Which conclusions are allowed by this motive and this partioning?

2. Does there exist a point at the qualitative interpretation when entering a higher graded niveau of connecting the different single piece of information, which can be nomed where there will be a contradiction which only can be named mistake (without quotation-marks!)?

To the first question:

18 feet or $9 \times 2$ feet can be interpreted as the 18 months of the Mesoamerican calendar. Feet as a partition of the year were treated in encyclopedian form collecting ethnographic and ethnohistorian sources by Thompson (1950:248). The Jacaltecs's eight foot of 40 days (plus a 9 th $^{3}$ that is not counted, but is formally to be expected) of the year proove that the foot is fit for a division of the year in Mayan-conceptions. There seems to be certain contradictions to the number 18 of feet here. For passing over them one should treat them as 18 feet as well as 9 feet, this either by thinking of 9 positions of stillstand with both feet or by regarding that the left feet in the pairs are in the outer space when the interior is defined by the rows of points of the RC and connect this with the name of "bolon oc/yoc/yocté" of the wellknown literature of the early colonial time. For further comparison Codex Dresden $25 c-28 c$ is to be referred to for prooving the thesis "year".

3 This might be doubted for the Jacaltecan case if is argued that the steps have to keep in the frame of one year. The nineth step in most cases will end in the following year when taken the day-sign oc as day of reference. But see also Codex Dresden 25c-28c where there are nine footprints which might stand for nine feet but 8 steps if such a distinction can be made or otherwise it would be in opposition to the above objection. 
There, in the frame of describing the ceremonies in advance of the new year, 9 feet are painted on ritual stelae or the textiles decorating them. Further on, a theme year is in between of the already recognized themes of CM 75-76.

The grouping of the single feet into different sorts of pairs parts the year in three pieces. Such a division into thirds of the year was found by Barthel (1964:77-101) already once, though in Aztecan context. Whether an astral, meteorological or seasonal interpretation can be connected to this cannot be subject here for it will lead us to far away from the aims of this study. A meaningful interpretation of the motive seems obvious and its results aren't in contradiction to recognized themes.

Let us turn to the second question.

The question shows that it is implicitely operated with a theoretical model of linguistics. ${ }^{4}$ This theory handles a system or a model, which aren't different in respect to the usage of the theory, as different graded connections of an endly number of single statements whose connecting is the author's intention. The number of connections determines the grade of the, if you like it, "texts". There exist hierarchically ordered and other connections that cannot be fixed in the hierarchy. A more precise and detailed formulation of this theory must be dispensed because of lack of space as well as a description of the following example referring to it very explicitely. Latter wouldn't conform with the Maya author's way of thinking. For the search of mistakes which have no explanation, I will give at first a more detailed description of the arrangement of the single feet.

Two feet are standing parallel to each other having the same direction and therefore can be named pairs. These pairs are set one behind the other and are directed to the center. The pairs of left feet are found in the lower left corner completed by the front pair of the lower right corner. The pairs of right feet of the upper left corner are completed in the upper right corner, front pair, the natural pairs of the upper right corner, middle and back pairs, find their completion in the lower right back pair.

4 This theory can be developed independently from CM 75-76 itself. 
One realizes: Combinations of the same type of pair are grouped together as far as possible. A missing pair is always in the neighbouring corner, never in the opposing. There is only one interruption in this corner-spreading arrangement, i.e. between west and south corner. (The only alternative in principle would have given two interruptions when excluded the alternatives with completion of all pairs in one corner or an always alterating arrangement of the pairs and unstructured distributions.)

A next order to the corner-spreading arrangement is the directing to the center. This order cannot be fixed in the hierarchy. It can be fullfilled everytime into an already complete arrangement.

By inclusion of the last piece of information the highest level of information is reached. The pairs are set one behind the other. Following the principle way of reading of the chapter, i.e. counterclockwise as determined by the RC there is found a discontinuity in the lower right corner. A natural pair precedes (!) the last pair of left feet if the position of the toes defines the direction of reading. This mistake is on the eastside. ${ }^{5}$ On this normally priviledged world-direction one had to expect the start of the series. This is opposed by the cornerspreading continuum with its discontinuity on a lower level of connected information. The start of the series on the south side is a yet unsolvable problem. It has to be remembered that the year-bearer of the south corner is 1 lamat. This is the start of the CR in Codex Paris 19-20, in the east corner it is 1 ben which according to Barthel $(1952: 45)$ starts the CR in Codex Dresden 25-28. Former opinion would give support to the reconstruction of a number 13 as day-number in the cartouche of day-signs, especially for the day-sign akbal, which belonging to the classic-style system of year-bearers is opposed

5 Whether this mistake is eventually a "mistake" cannot decided yet. An interpretation as processional route on which was moved forwards in the north and south corners and backwards in the east and the west corners as done in an earlier-version of this paper is because of lack of evidence as speculative as, which runs in front further description and argumentation, an accentuation of the east corner as begin of the CR starting with a year 2 ben -in its equivalent 2 reed known from Aztecan sources- in opposition to a CR-quarter-division beginning the count with a year-number 1 . 
in its positional preference in the correct parts of the arrangement to the other year-bearers of this style and which would lead to 1 lamat as the next year. By this the final days of the Trecenas would get further meaning, but this is speculative.

An, at least partially, intended mistake-making (types of pairs) can be recognized. At the beginning there can always be found an explanation on the next higher level of associating information. Reaching the highest level, that can be recognized, a contradiction can be noticed (discontinuity in the east corner). Whether there is a second cannot be decided because of concurring traditions. In this case, in one instance, there are doubts about the reliability of the scribe. This is (the case in) a case which wouldn't be mentioned among the first (mentioned) mistakes and, (this) in my opinion, pleads for more reliability of the author and writer than commentaries wanted to make us believe.

The method of maximizing information is used again though, as far as it can be judged so far, not in the last consequence.

The equalization of a foot ${ }^{6}$ as a part of the year is to be accepted as the author's foreknowledge which he premised for the reader and operated with it therefore. This latter is given further support as well as to the possibility to deduct it from the context. This time it is prooved by our knowledge about the concept in the background, i.e. the Jacaltecan foot of the year (Thompson 1950:248).

\section{THE WHITE FRAMES}

Further on the feet possess elements which have to be seen as information, i.e. white frames and rows of points, mounting to three rows; of two different sizes which in most cases can be called toes with the exception of those four sets of rows which are found behind some of the feet of the last row in 3 corners. The interpretation of the points of bigger size, which are generally still smaller than the points of the Trecenas, and

6 It is interesting to note that Mesoamerican Indians used the foot for measuring lenghts in the space as well as of time. 
organized in a different way than those, will be done in another context (P. Jüngel: in prep.). Their number is smaller than that of the smallest size. The latter I shan't analyse because of conservatorian reasons.

The white frames mark special parts of the outline of the feet and do not look as one another. Though 4 feet are damage in a way that no last security can be achieved about the range of the frame, I believe that it is still possible to determine by minimal survivals whether a certain section owned such a frame.

How are these sections to be named?

I distiguish

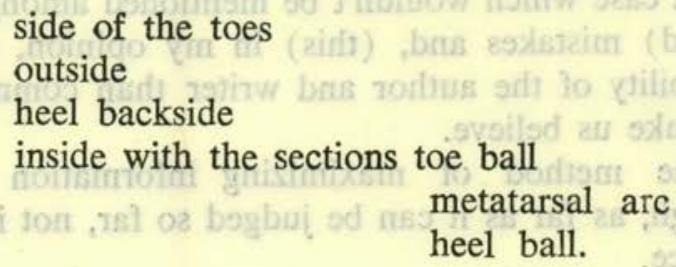

This latter division is only important in respect to type 4. The types as well as their distribution are shown in fig. 1.

Two doubty cases (CM 75 bottom: left front, and 75 top: right front) are noted as members of the 12 cases of type 1 , i.e the whole inside is framed. Both are insecure on the side of the toes only. The corner of the side of the toes to the outside is not destroyed and shows no frame for the questioned side.

Type 2 is exclusively to page 76 . The inside and the heel backside possess the frame. Its two representants are page 76 bottom: left back; and up: right front.

Type 3 , page 75 bottom: right back, adds the side of the toes to the inside.

Type 4 , a single member on page 75 bottom: right front, is framed only on the inside, this is sure, and there surely at the toe ball and the metatarsal arc. The connection to the heel ball is destroyed by a fold and off-splits as effects of the fold so that the area of the heel ball rests doubtful. Type 1 seems to be the less likely alternative in this case. So I treat this example as a special type. 
Type 5, page 75 up: left front, is without frame only on the heel backside. The bordering area of the heel ball on the inside is uncleared by crossing folds, a big one and two smaller ones. One believes to see a change of direction of the frame for forming a parallel to the heel ball in the inner corner of the metatarsal arc as well as an ending at the back of the heel ball. This insecurity excepted this foot still remains an individual type.

Type 6 corresponds to type 5 as it only leaves the side of the toes without frame, i.e. the opposing side of type 5 . Its member is found on page 76 bottom: right back.

12 feet, the two insecure mentioned included, possess the frame on the whole lenght of the inside. They are arranged in 4 pairs and 4 others which are not paired with members of type 1 , i.e. a relation of 8 (in pairs) to 4 single feet or a relation $2: 1$.

For the exclusive type 6 feet remain. The relation 12:6 parts the year in thirds in the relation $2: 1$ and gives further support for the division of the year into thirds made by the pairs of feet. This 6 unnormal cases consist of 4 single membered types and $a$ once repeated form which end in another relation $2: 1$. These 6 feet are once arranged in pairs (lower right) so that there will be still another relation $2: 1-4$ unpaired to one paired members of exclusive types (see fig. 1 distribution).

If one examines the positional distribution it is to be noticed, once more, the already mentioned relation $2: 1$. On top of the pages there are 2 members of exclusive types, at the bottom there are four. This can still be noticed in a right-left dichotomy. The normal case therefore must follow this topbottom opposition, too, turning it $180^{\circ}$, top 8 , bottom 4 .

This description depends very much on my critical judgement of parts affected by destruction in the source itself and whether it can be accepted by my colleagues. The only control I possessed was my decision of type before I recognized of supposed any principle of organisation, respectively believed to have recognized it.

I cannot offer any interpretation for this relation 2:1.Though the redundant insistancy cannot produce any doubts of its being meaningful. 
This redundance I have already found more than once in this chapter thought not yet used for one type of information only but for different types (of information) which could work as independent models of information making up the themes "year" and "shift of year-bearers". This redundance of contents can be compared with the partial redundance of given information in the initial series of the long-count and the couplets of Mayan literature. Redundance can't be taken as selfconfirming in the sense that the decipherer only believes to find it and by this confirms himself the believed structure but as intended and one can call them "couplets of the formal structure of codices and their chapters" as the analog to other forms of expression of Mayan culture. By this redundance can eventually have be a control for decipherment after it has actually be done.

With this result a further abstraction and demand can be added to those formulated at the beginning. The results of the examination of CM 75-76 done so far can be formulated thus:

Mistakes have to be prooved as mistakes before it is possible to correct them uncritically. It could be "mistakes", i.e. changements of a given scheme for further information to the user.

Redundances are formal couplets.

Sometimes it is an author's principle of work to maximize intentions to be fulfilled though using minimal devices.

The writer of $\mathrm{CM} 75-76$ is more reliable than believed before.

Finally I will offer some consideration on the position of CM 75-76 in the whole of the codex and on questions further to be solved.

The impression evolves that this chapter is an index to the themes treated in this manuscript, especially to CM 65-73b. Thus, Barthel (in prep.) has found an arrangement in the form of a magic square in the upper register of $\mathrm{CM} 65-73 \mathrm{~b}$, that is a square in which numbers, here of the geometric positions of the pictures, sum up to the same result in the diagonals, lines and columns. As well as sums of astronomical meaning there is found a model of the believed world in 4 strata with a crossroad set on it. This magic square can be understood as a maltese-cross with crossroad. The cross-road of CM 75- 
76 is found in the points named toes (P. Jüngel: in prep.), CM 75-76, at least, needs the existence of CM 65-73b as well as that of CM 34-37, so that the aspect of calendar reform can be deduced by other sources or their interaction. There are also to be named the special role of "life" and "death" (change of the respective day-signs in the cartouche of $\mathrm{CM}$ $75-76$, combination of the gods in picture 22 of CM 65-73) and the unusual depiction of figures sitting back to back in their respective temples in the central picture of CM 75-76, and in picture 19 of $\mathrm{CM} 65-73 \mathrm{~b}$.

An examination of CM 75-76 that intends a complete commentary of this chapter has to start from these new insights and the resulting questions.

First of all to answer is the series in which the mistakes were included in the systems as far as there possibilities of first signs. This is also true for the day-signs. The series of mistakes recognized are only the series in which the analyser has to find the mistakes, not naturally that of the Maya-author's mistake-making.

These studies have to include the position of the calendar formed by the feet in relation to the seasonal cycle; thereby the right-left-dichotomy might be useful. Problematic will be whether natural pairs are seen as natural and therefore positive or just as a combination of right and left foot.

Further on, the meaning of the white frame and together with this its structured distribution is to be cleared. Mayatermini for different parts of a foot as those for step, instep, outstep, heel, toe, ball and sole are needed. How much a complementary-contrasting choice of forms is important, is still open for question. In this detail we might meet a partly conscious, partly unconscious setting in order of chaos.

It is to be studied once more the problem of the westerned arrangement because it isn't still satisfyingly solved and which is in opposition to the east as main-direction. The arrangement of the day-signs in the cartouche, however, can be taken as being in accordance with an easterned picture of worlddirections. Is the westerned arrangement indirectly dependent to that the mistake-making in the cartouche had to culminate in the east while the realized aims couldn't achieved otherwise? This is open to future study. 
There is to be included iconography as well. This must be done in comparison to CFM 1. It isn't quite unattractive to interprete the two gods in the central picture of CM 75-76 as Tonacacihuatl and Tonacatecuhtli, respectively their Mayan equivalents as (Seler 1901:30) took into account, but this is in contradiction to a pair that would be expected in dialogue with one another by sitting confronting each other. Because of a pair in the center there are 10 gods in $\mathrm{CM} 75-76$ while there are only 9 in CFM 1 . These latter can be connected to the 9 lords of the night (see Seler 1901:5-28), Seler (1901:31) had to give up this attempt and to hope for the future in the case of $\mathrm{CM} 75-76$. Though it is recommended to look for alternatives partially unknown to Seler, in respect of interethnic adaptation one should not give up Seler's attempt, especially as there is possible a new start. Barthel (in press with further bibliography) noticed a change of sex between CFM 1 ( 2 goddesses in the west) and the earlier, i.e. from early classic times, "bowl of 9 hieroglyphic gods" (see Hellmuth: 1987:284 fig. 634) (one goddess and one god in the west) which would fit to CM 75-76 where there also is a pair (of either sex) in the west. The appropriatness of this observation for CM 7576 has to be prooved yet. 


\section{ABBREVIATIONS}

CFM Codex Fejérváry-Mayer

CM Codex Madrid

$\mathrm{CR}$ calendar round

ICA Internacional Congress of Americanists

$\mathrm{RC}$ ritual-calendar

\section{BIBLIOGRAPHY}

Barthel, Thomas S.

1952 Studien zur Entzifferung astronomischer, augurischer und kalendarischer Kapitel in der Dresdener Mayahandschrift - Ein Beitrag zur mittelamerikanischen Altertumskunde. Dissertation, Hamburg (Ms.)

1964 "Einige Ordnungsprinzipien im aztekischen Pantheon". Paideuma 10 (77-101).

1988 "Ein früher Schlüssel zur Indo-Mexikanistik". Indiana 12 (in press).

o.J. Die Sonne ist rot. (in prep.).

Codex Dresden

1962 Berlin.

Codex Fejérvary-Mayer

1971 Graz.

Codex Madrid

1967 Graz.

Codex Paris

1968 Graz.

Cordemex

1980 Diccionario Cordemex Maya-Español - Español - Maya. Mérida.

Förstemann, Ernst W.

1902 Commentar zur Madrider Mayahandschrift. Danzig (was not available).

Hellmuth, Nicholas M.

1987 Monster und Menschen in der Maya-Kunst Eine Ikonographie der alten Religionen Mexikos und Guatemalas.

Graz. (also in English translation available). 
Jüngel, Peter

o.J. Götter. Mond und Ballspielplätze - Uber die interethnische Anwendbarkeit von Modellen am Beispiel des Ballspiels in Mesoamerika, (preliminary title) Dissertation, Tübingen (in prep.).

Nowotny, Karl A.

1961 Tlacuilloli - Die mexikanischen Bilderhandschriften. Berlin.

Seler, Eduard

1901 Codex Fejérváry-Mayer eine altmexikanische Bilderhandschrift der Free Public Museums in Liverpool (12014/ M) Berlin.

Thies, Frauke J.

1979 "Analyse und Interpretation der Seiten 75 und 76 und der 12. und 13. Zeile der Seiten 78 und 77 des Codez Madrid". International Congress of Americanists 42,7 (1976), Paris (259-266).

Thompson, J. Eric S.

1950 Maya hieroglyphic writing - An introduction. Washington, D.C.

1972 A commentary on the Dresden Codex. Philadelphia.

Tozzer, Alfred M.

1941 Landa's Relación de las cosas de Yucatán: a translation. Cambridge, Mass. 


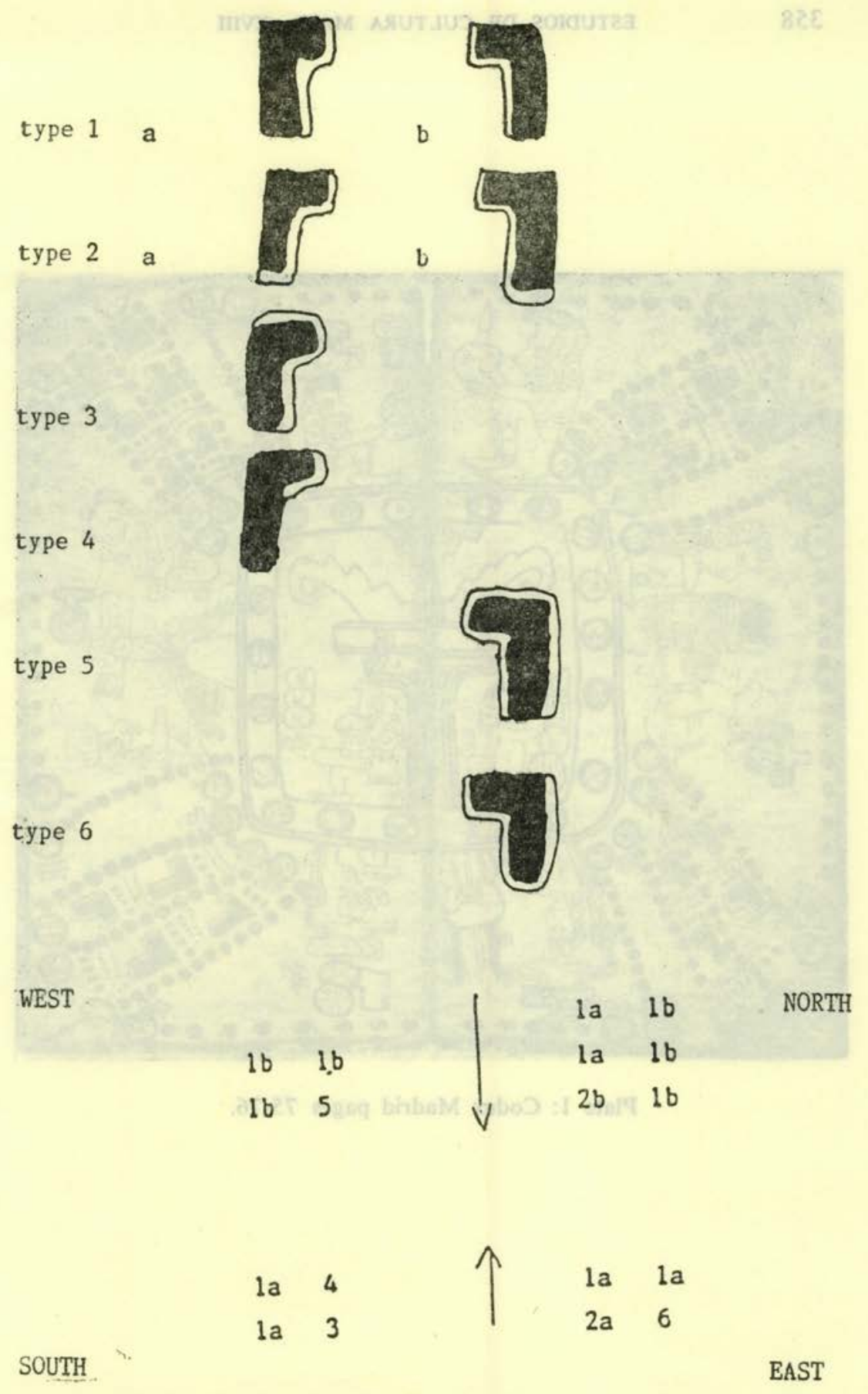

Fig. 1: Types of white frames and their distribution (arrows point into the direction of the toes.) 


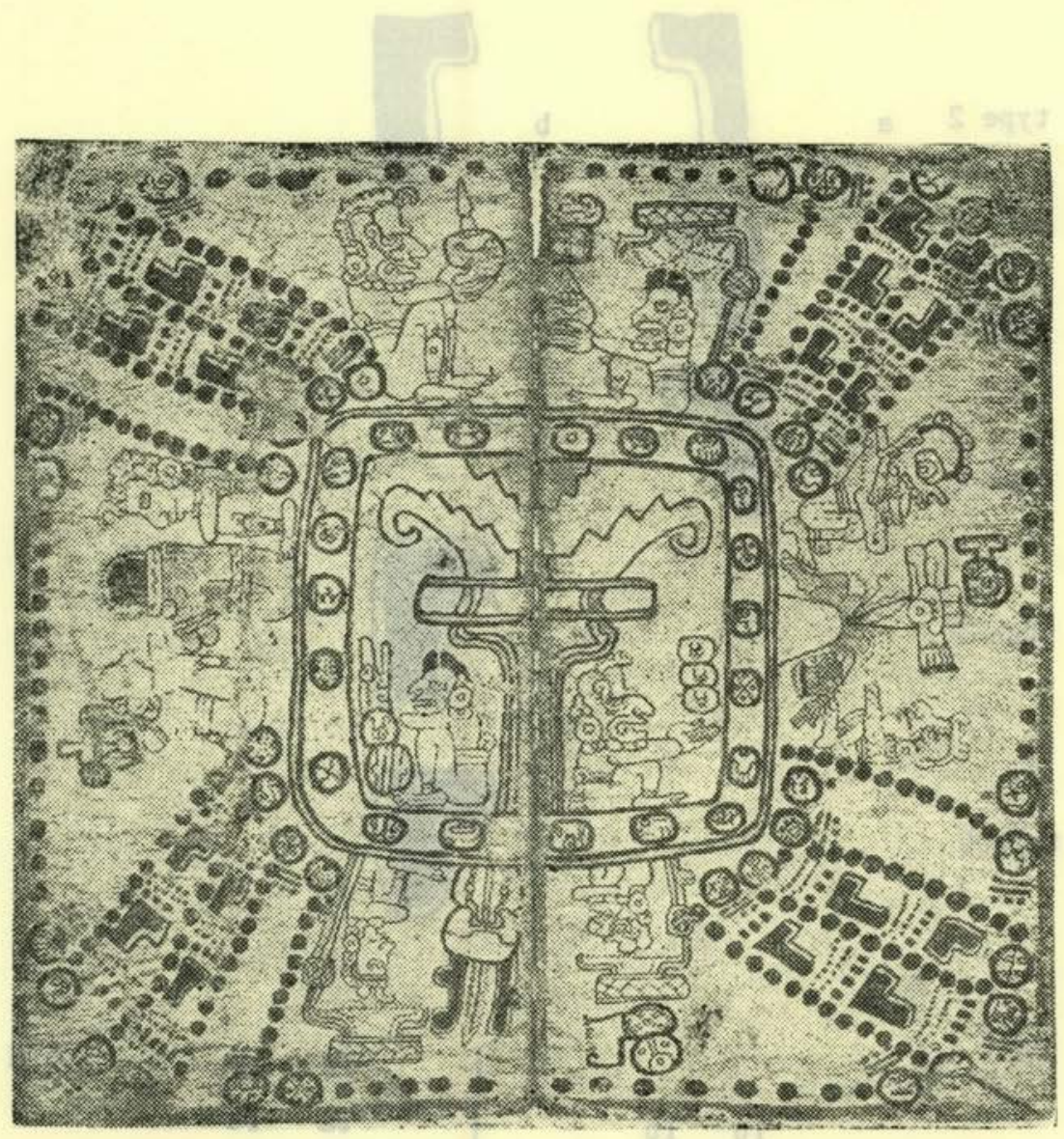

Plate 1: Codex Madrid pages 75-76. 